\title{
PENERAPAN DATA MINING UNTUK EVALUASI KINERJA AKADEMIK MAHASISWA (STUDI KASUS: UMTAS)
}

\author{
Sulidar Fitri \\ FKIP, Program Studi Pendidikan Teknologi Informasi \\ Universitas Muhammadiyah Tasikmalaya \\ Email: sfitri@umtas.ac.id \\ Novi Nurjanah \\ Fakultas Teknik, Program Studi Teknik Lingkungan \\ Universitas Muhamamdiyah Tasikmalaya \\ Email: novi@umtas.ac.id \\ Windi Astuti \\ FKIP, Program Studi Pendidikan Teknologi Informasi \\ Universitas Muhammadiyah Tasikmalaya \\ Email: windiastuti301@gmail.com
}

\begin{abstract}
ABSTRAK
Harapan masyarakat secara umum sangat besar yaitu supaya institusi pendidikan dapat menyelenggarakan pendidikan yang berkualitas bagi mahasiswa sehingga menghasilkan keluaran berupa sumber daya manusia yang terampil, berilmu, cerdas dan berkualitas. Penerapan Data Mining dilakukan untuk dapat mengukur kinerja akademik mahasiswa di Universitas Muhammadiyah melalui pengukuran pada Indeks Prestasi Akademik (IPK) sebagai yang utama. Keberhasilan dalam memperoleh IPK yang tinggi biasanya dipengaruhi oleh banyak faktor salah satunya adalah jam berlajar mahasiswa tersebut. Banyak mahasiswa di lingkungan Universitas Muhammadiyah Tasikmalaya (UMTAS) menjadi pengguna Internet aktif dan menjadi indikasi faktor pengganggu dalam kegiatan belajar mahasiswa. Dalam penelitian ini akan dilakukan penerapan data mining dengan mengklasifikasikan melalui aturan atau rule algoritma Decision Tree mahasiswa berdasarkan IPK yang diperoleh pada semester sebelumnya. Selanjutnya, untuk mengetahui pengaruh yang signifikan dari faktor-faktor yang ada menggunakan metode penghitungan chisquare. Hasil dari penelitian ini menunjukan bahwa hasil prediksi dari data uji memberikan angka sebesar 84\% mahasiwa memperoleh IPK Tinggi dan 16\% sisanya memperoleh IPK Sedang. Untuk uji menggunakan chi kuadrat dapat menunjukan bahwa adanya nilai yang signifikan antara Penggunaan Media social terhadap nilai IPK. Ternyata, hasil berbeda terjadi pada hubungan antara waktku belajar terhadap niliai IPK yang tidak menunjukan adanya nilai yang signifikan.
\end{abstract}

Kata kunci: klasifikasi, prediksi, Internet, media sosial, pengguna internet, pengaruh media sosial.

\begin{abstract}
Public expectation in general is very large that can educational institutions can provide quality education for students so as to produce the absorption of human beings who are creatures, knowledgeable, intelligent and qualified. Implementation of Data Mining is conducted to be able to measure the student academic performance at Muhammadiyah University through measurement of Academic Achievement Index (GPA) as the main parameter. Success in high IPK (Indeks Prestasi Kumulatif or known as GPA results is usually by many factors one of which is the student's hours. Many students in the University of Muhammadiyah Tasikmalaya (UMTAS) become active internet users and become a disturbing factor in student learning activities. This research will be implemented data mining by classifying through rules or rules of student Decision Tree algorithm based on IPK obtained in the previous semester. Being aware of the significant effect of factors that exist by using chi-square counting. The results of this study show the prediction results from the test data give the number of $84 \%$ of students of High GPA and $16 \%$ of the remaining given GPA Medium. For the test using chi squared can show a significant difference between Social Media Usage to GPA value. Different results occurred in the relationship betweens study times, the GPA did not show any significant significance.
\end{abstract}

Keywords: classification, prediction, internet, social media, internet users, social media influence. 


\section{PENDAHULUAN}

Prestasi akademik yang diperoleh mahasiswa dianggap sebagai keberhasilan seorang mahasiswa dan system pembelajaran di institusi tersebut. Kualitas akademik tersebut juga tidak terlepas dari latarbelakang mahasiswa itu sendiri disamping sistem dan iklim belajar mengajar yang tercipta di lingkunganpendidikannya. IPK (Indeks Prestasi Kumulatif) yang baik tentunya membuat target masa studi tercapai dengan kualitas yang bagus. Masa studi yang tepat waktu mendorong berkurangnya penumpukan mahasiswa di semester akhir yangbisa mengakibatkan ratio dan kualitas yangtidak baik. Prestasi Akademik biasanya diukur melalui Indek Prestasi Akademik (IPK). Keberhasilan dalam memperoleh IPK yang tinggi biasanya dipengaruhi oleh banyak faktor salah satunya adalah jam berlajar mahasiswa tersebut.

Penambangan informasi dari data yang sangat besar atau data tersebut dikenal dengan istilah big data bertujuan untuk dapat menggali pengetahuan yang terdapat di dalamnya. Pengetahuan tersebut akan memberikan pola maupun rule yang dibutuhkan untuk menganalisis data selanjutnya. Teknik yang dilakukan untuk melakukan penggalian informasi tersebut dikenal dengan istilah data mining.

Proses yang dilakukan untuk mengekstrak pengetahuan dalam data mining adalah pengenalan pola, clustering, asosiasi, prediksi dan klasifikasi. Klasifikasi adalah pemrosesan untuk menemukan sebuah model atau fungsi yang menjelaskan dan mencirikan konsep atau kelas data, untuk kepentingan tertentu. Dalam proses klasifikasi ini terdapat beberapa macam algoritma pemrosesan diantaranya adalah algoritma C4.5 untuk membangun pohon keputusan.

Pada era big data dimana banyak sekali tumpukan data yang tertimbun di berbagai sektor menyebar dalam lapisan masyarakat luas memunculkan banyak sekali tools pendukung atau software aplikasi yang di desain untuk membantu manusia melakukan proses penambangan maupun penggalian pengetahuan dalam tumpukan data yang ada. Tools yang ada sangat membantu manusia untuk dapat mengetahui hasil akhir output yang dikehendaki. Pada kondisi dimudahkannya mendapatkan hasil atau output dalam proses penambangan pengetahuan perlu juga diketahui bagaimana langkah yang dilalui dalam mendapatkan hasil akhir yang dikehendaki.

Peningkatan yang sangat pesat dalam hal perkembangan teknologi tidak bisa dipungkiri lagi. Hal ini menjadi salah satu faktor yang diasumsikan mengganggu jam belajar mahasiswa dikarenakan menjadi trend secara global terutama di kalangan anak muda. Kemajuan teknologi dibuktikan dengan banyaknya keluaran perangkat gadget baru dalam berbagai merek yang sering kita lihat di pasaran. Bersamaan dengan semakin canggihnya perangkat gadget yang ada, maka sangat wajar jika fitur-fitur yang ada didalamnya pun mulai bervariasi untuk lebih memudahkan para pemakai gadget berteknologi tinggi. Begitu juga untuk kebutuhan bersosialisasi secara jarak jauhpun semakin banyak pilihan aplikasinya. Aplikasi media sosial jarak jauh ini banyak disediakan oleh perusahaan penyedia apliasi untuk smartphone.

Indonesia merupakan negara berkembang juga mempunyai minat yang cukup tinggi terhadap perkembangan teknologi lebih khususnya ketertarikan yang cukup tinggi terhadap beberapa situs jejaring sosial. Seperti informasi yang didapatkandari hasil survey APJII (Asosiasi Penyelenggara Jasa Internet Indonesia) mengenai tingginya pengguna internet di Indonesia mencapai 132,7 juta jiwa pada tahun 2016 dari total 256,2 juta orang total populasi penduduk Indonesia. Berdasarkan angka yang ada, maka terjadi kenaikkan sebesar 44,6 juta dalam waktu 2 tahun (2014 - 2016). Dari total populasi yang ada, sebesar 47,6\% atau sebanyak 63,1 juta penduduk menggunakan perangkat smartphone (perangkat mobile) untuk mengakses internet. Sedangkan konten situs jejaring sosial yang sering dikunjungi khusus aplikasi instagram di indonesia sebesar $15 \%$ atau 19,9 juta orang pengguna [2].

Banyak mahasiswa di lingkungan Universitas Muhammadiyah Tasikmalaya (UMTAS) menjadi pengguna Internet aktif. Hal ini sangat terlihat dengan jelas apabila kita datang melihat ke beberapa area di kampus tersebut yang merupakan tempat para mahasiswa berkumpul dan online menggunakan smartphone. Berdasarkan obesrvasi langsung terlihat bahwa 7 dari 10 mahasiswa dalam satu kelompok sedang melakukan surving internetdengan menggunakan smartphone.

Maraknya pengaksesan aplikasi media sosial dikalangan mahasiswa membuat para pendidik harus waspada akan pengaruhnya terhadap nilai akademik mahasiswa karena focus dan perhatian mereka dapat teralihkan lebih banyak ke situs jejaring sosial tersebut. Kewaspadaan ini sangat beralasan karena berdasarkan hasil survey, pengguna internet di Indonesia sebesar 18,4\% atau 24,4 juta orang dengan usia 10-24 dimana usia tersebut merupakan usia sekolah produktif [2].

Menurut beberapa penelitian yang telah dilakukan berkaitan dengan dampak sosial media, ada yang menyimpulkan bahwa sosial media memberikan dampak yang sama antara positif maupun negatif terhadap performa akademik mahasiswa tergantung bagaimana mereka memanfaatkannya [8]. Selanjutnya pada penelitian lain yang dilakukan menghasilkan kesimpulan bahwa penggunaan sosial media berpengaruh negative terhadai peroforma akademik mahasiswa apabila memiliki manajemen waktu yang baik dalam penggunaan media sosial [1]. 
Kesimpulan menarik dari penelitian yang dilakukan oleh Raj Kumari Kalra dan Preeti Manani tahun 2013 menyatakan bahwa mahasiswa dapat mengelola waktu mereka secara efisien dan karenanya, penggunaan Situs Jaringan Sosial tidak tidak membahayakan kinerja akademis mereka. Temuan menunjukkan bahwa meskipun menghabiskan waktu di internet atau menggunakan Jaringan Sosial, Situs, dan bahkandengan kepribadian perbedaan mahasiswa cukup efisien untuk studi mereka dan mereka tidak menghadapi kekurangan apapun dalam memenuhi kebutuhan studi mereka [9].

\section{METODOLOGI PENELITIAN}

Metode penelitian ini menggunakan algoritma klasifikasi dari data mining bernama Decision Tree untuk melihat pola dan mendapatkan rule pencapaian IPK mahasiswa. Metode pengumpulan data yang digunakan adalah metode survey untuk mendapatkan data primer dari para responden. Sedangkan untuk mengetahui nilai signifikan pengaruh dari beberapa faktor terutama waktu belajar dan lamanya pengaksesan media social terhadap IPK akan menggunakan metode perhitungan statistic chi-square.

Indeks Prestasi Kumulatif mahasiswa akan dikategorikan dalam 3 tingkat yaitu rendah $(<2.50)$, Sedang $(>=2.50$ dan $<3.50)$, dan Tinggi $(>=3.50)$. Proses pengerjaan klasifikasi untuk memprediksi perolehan IPK mahasiswa dapat dilihat dari gambar 1.

Berdasarkan literature yang ada akan dilalui proses pengklasifikasian, pemodelan, menemukan pola, sampai memprediksi data akan tampak lebih jelas seperti yang dipaparkan pada gambar 2. Pada gambar 1, dimulai dengan memasukan data uji hasil koleksi dari data mahasiswa kemudian dilakukan penerapan model. Penerapan model dilakukan setelah mendapatkan model dari masukan data latih yang telah diproses dengan algoritma Decision Tree. Hasil didapat setelah output keluar. Gambar 2 merupakan proses klasifikasi menggunakan data latih kemudian diproses dengan learning algorithm maka jadilah model yang kemudian diimplementasikan untuk digunakan pada data uji.

\subsection{Prosedur}

Para responden yang terdiri dari mahasiswa di minta kesediannya secara sukarela untuk mengisi survei yang berupa kuisioner.Responden diminta untuk masuk ke link website yang akan disediakan atau mengisi kuisioner secara manual melalui lembaran-lembaran yang akan dibagikan. Responden diminta mengisi semua pertanyaan-pertanyaan yang ada pada kuesioner. Untuk memudahkan responden dalam mempelajari kuesioner dan menjawab pertanyaan-pertanyaan yang diberikan, maka pertanyaan dibagi menjadi 2 bagian, yaitu:

a. Bagian pertama, yaitu mengenai data demografi dari responden. Responden ditanyakan perihal jenis kelamin, jam berinternet, status aktif menggunakanmediasosial, semester, IPK, aktif kegiatan UKM (Unit Kegiatan Mahasiswa), dan waktu belajar.

b. Bagian kedua, kuesioner yaitu pengumpulan data dengan jalan membagikan daftar pertanyaan untuk dijawab oleh responden yang telah ditentukan.

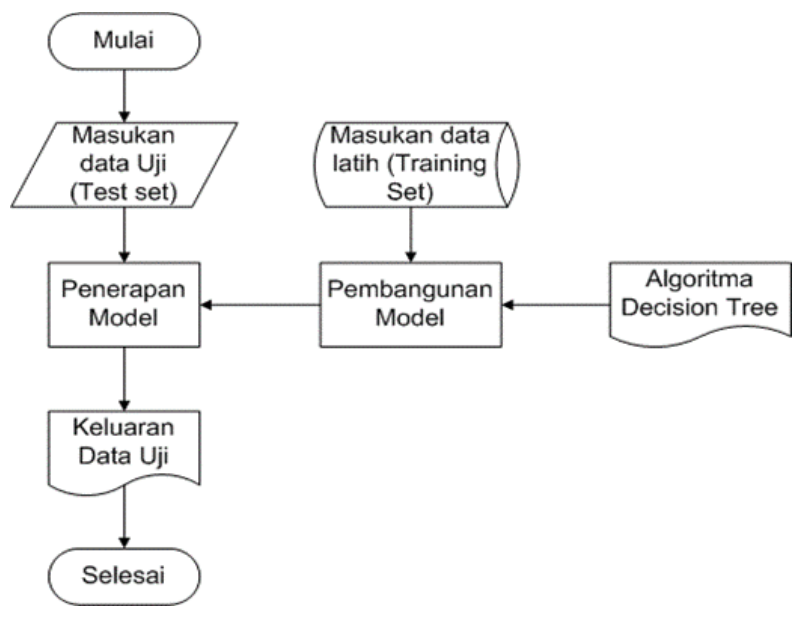

Gambar 1. Flowchart Pengerjaan Klasifikasi Data 


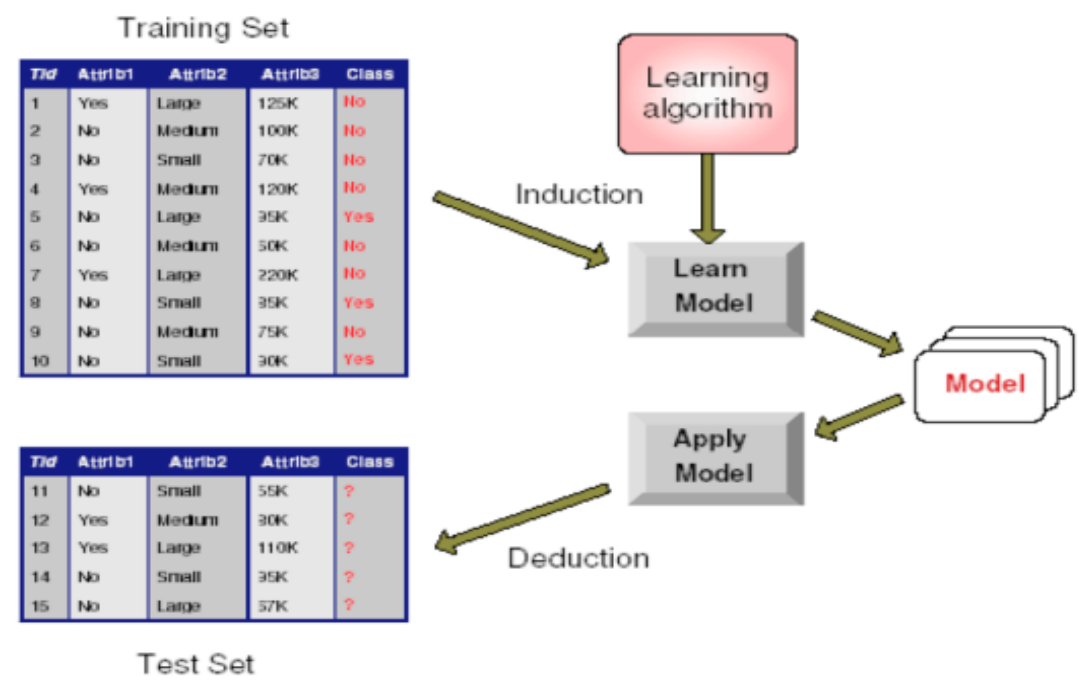

Gambar 2. Proses Pengklasifikasian Data [12]

\subsection{Analisis Data}

Metode analisis yang akan digunakan adalah algoritma decision tree c4.5 untuk mengklasifikasikan, membuat model, menemukan pola, sampai menemukan rule untuk dapat memprediksi data yang diujikan. Sedangkan perhitungan statistika chi-square akan digunakan untuk mengetahui nilai signifikan pengaruh dari variable waktu belajar dan penggunaan media social terhadap nilai IPK mahasiswa. Apabila nilai $\mathrm{p}$ mencapai angka $<0,05$ maka hipotesis $(H 1)$ yang menyatakan adanya hubungan akan diterima. Namun apabila nilai $\mathrm{p}>=0,05$ maka hipotesisnull $(H O)$ yang menyatakan tidak ada hubungan akan diterima.

Pada penelitian ini Hipotesis untuk H1 yang pertama adalah "Penggunaan Media Sosial memberikan pengaruh negative bagi nilai akademik (IPK) mahasiwa UMTAS" seperti yang tertera pada gambar 3. Sedangkan gambar 4 menjelaskan bahwa sebagai hipotesis yang kedua, H1 merupakan "Waktu Belajar mahasiwa memberi dampak positif terhadap nilai IPK". Dalam hal ini, model teori untuk variable independent adalah aplikasi instagram dan variabel dependent yang digunakan adalah nilai akademik (IPK) mahasiswa UMTAS.

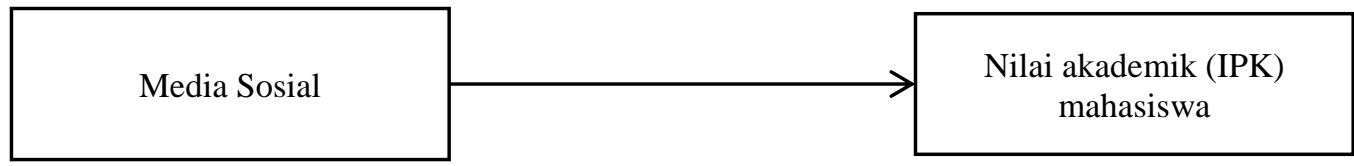

Gambar 3. Model Untuk Penggunaan Media Sosial

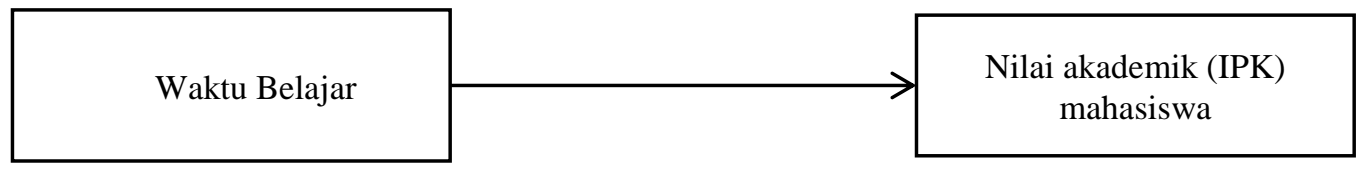

Gambar 4. Model Teori Untuk Penggunaan Media Sosial

\section{HASIL DAN PEMBAHASAN}

Penelitian ini menggunakan dataset yang dikumpulkan dari menyebarkan angket secara acak kepada mahasiswa semester 3 di Universitas Muhammadiyah Tasikmalaya (UMTAS) angkatan 2016. Data latih yang digunakan adalah sebanyak 100 data terdiri dari 26 mahasiswa memiliki IPK (Indeks Prestasi Kumulatif) kategori Rendah, 29 mahasiswa memiliki IPK kategori Sedang, dan 45 mahasiswa memiliki IPK kategori Tinggi. Sedangkan data yang digunakan sebagai data uji yang akan diprediksi kategori IPKnya adalah sebanyak 50 data mahasiswa semester 1 . Tahapan berikutnya yaitu melakukan preprocessing data yang meliputi beberapa cara yaitu: 
a. Menghapus data yang memiliki outlier/noise, data yang tidak konsisten dan data yang tidak lengkap (missing value). Pada data uji dan data latih, atribut Prodi, Fakultas dan Jenis Medsos memiliki missing value sehinggadihapus agar tidak mempengaruhi tingkat akurasi pada hasil evaluasi nantinya.

b. Melakukan Transformasi data dimana dalam tahap ini value dari beberapa atribut dirubah datanya menjadi jenis kategorikal Rendah, Sedang, dan Tinggi. Beberapa atribut yang dimaksud adalah Nilai Kehadiran, Jam Berinternet, Waktu Belajar, Waktu menggunakan Medsos, dan IPK.

c. Melakukan Pengurangan data maupun Deskritisasi data dimana apapun nilai data yang berisi tipe numerik dirubah menjadi data kategorikal.

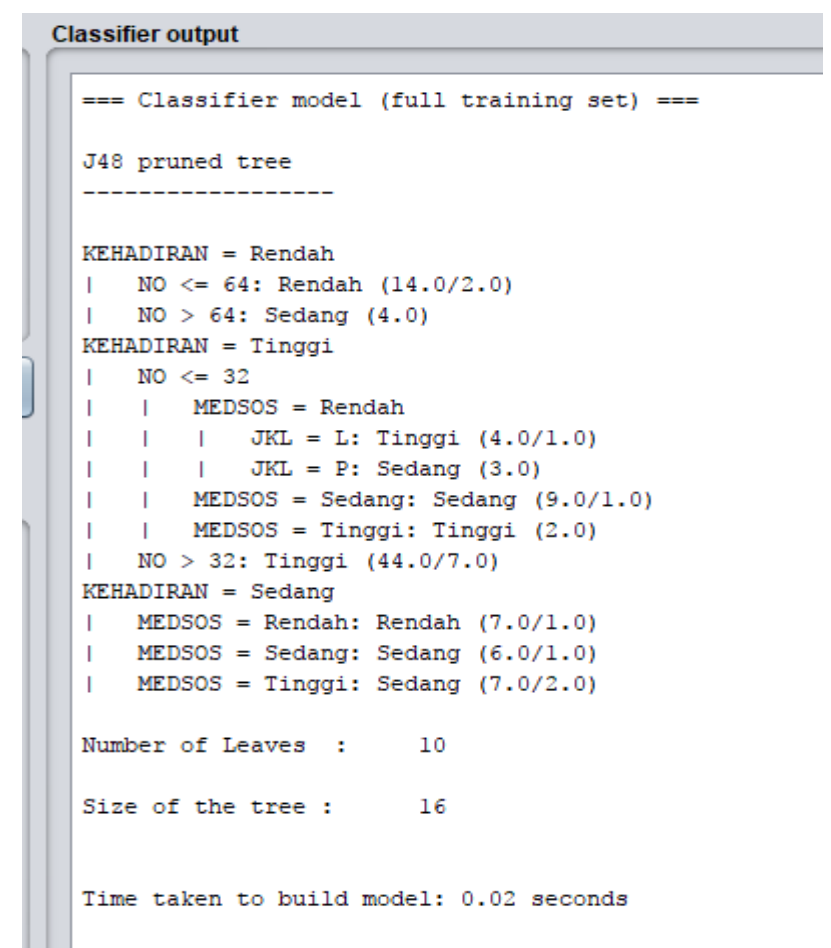

\section{Gambar 5. Hasil Klasifikasi Menggunakan WEKA}

Setelah dilakukan tahap preprocessing data didapatkanlah beberapa atribut yang akan diuji dalam penerapan datamining kali ini. Beberapa atribut tersebut diantaranya Jenis kelamin, Nilai Kehadiran, Jam Berinternet, Waktu Belajar, Waktu menggunakan Medsos (Media Sosial), dan IPK.

Dalam pembangunan model yang digunakan pada penelitian ini adalah klasifikasi dengan algoritma J48. Dalam tahap ini, data yang digunakan untuk data latih sudah memiliki target kelas pada atribut IPK yang memiliki nilai seperti Rendah, Sedang, dan Tinggi. Setelah tahap pembangunan model maka dilanjutkan untuk dilakukan Pengujian dan Evaluasi. Pada tahap ini dilakukan pengolahan data uji untuk memprediksi target kelas yang merupakan atribut IPK dan masih kosong atau tidak memiliki nilai isian. Pada tahap Evaluasi akan dilakukan pemrosesan data untuk mengetahui nilai akurasi dari model yang ada sebagai acuan model untuk memprediksi data uji.

Pada gambar 5 terlihat bahwa hasil dari pengolahan WEKA Classifier hanya memilih atribut Kehadiran, Medsos, dan Jenis Kelamin sebagai atribut dalam pohon keputusan, sedangkan atribut yang lain langsung terpangkas dari pohon keputusan. Dapat disimpulkan bahwa dengan jumlah dan jenis data yang ada hanya dibutuhkan beberapa atribut untuk mendapatkan kelas output dari dataset tersebut. Pohon keputusan yang terbentuk secara visual dapat dilihat pada Gambar 6.

Pada tahap evaluasi telah dilakukan pengukuran keakuratan hasil yang telah dicapai. Berdasarkan uji coba pembacaan pohon keputusan dengan sinkronisasi data set, pada kasus ini algoritma C4.5 memiliki tingkat akurasi yang tidak sampai mencapai $100 \%$. Akurasi klasifikasi didapatkan berdasarkan gambar hasil summary pada gambar 7. Data hasil pemrosesan yang sangat penting dicermati adalah pada bagian Classified Instances karena menentukan apakah hasil pemodelan tersebut dapat diterima atau tidak.

Hasil summary pembuatan model yang diperlihatkan pada gambar 7 mencatat bahwa Total number of instances ada sebanyak 100. Hal tersebtu mengartikan bahwa tidak ada missing data dan semua data dari data uji berhasil diproses. Hasil pemodelan dari 100 data latih yang digunakan untuk membuat tree pada 50 data uji telah mendapatkan hasil akurasi yang terbilang cukup bagus. 
Berdasarkan hasil summary yang merupakan rangkuman hasil proses yang dilakukan didapatkan tingkat akurasi klasifikas algoritma C4.5 sebesar $85 \%$ yang disebut sebagai prosentase dari Correctly Classified Instances. Correctly Classified Instances merupakan banyaknya data yang diklasifikasikan secara benar dengan menggunakan model yang ada. Angka ini terbilang cukup besar dan dapat diterima karena hampir mendekati 90\%. Sedangkan sisanya sebesar 15\% merupakan prosentase Incorrectly Classified Instances. Incorrectly Classified Instances merupakan data yang diklasifikasikan namun terjadi error atau tidak sesuai dengan model yang dibangun di awal. Angka ini masih tergolong rendah dan hasil klasifikasi dapat diterima.

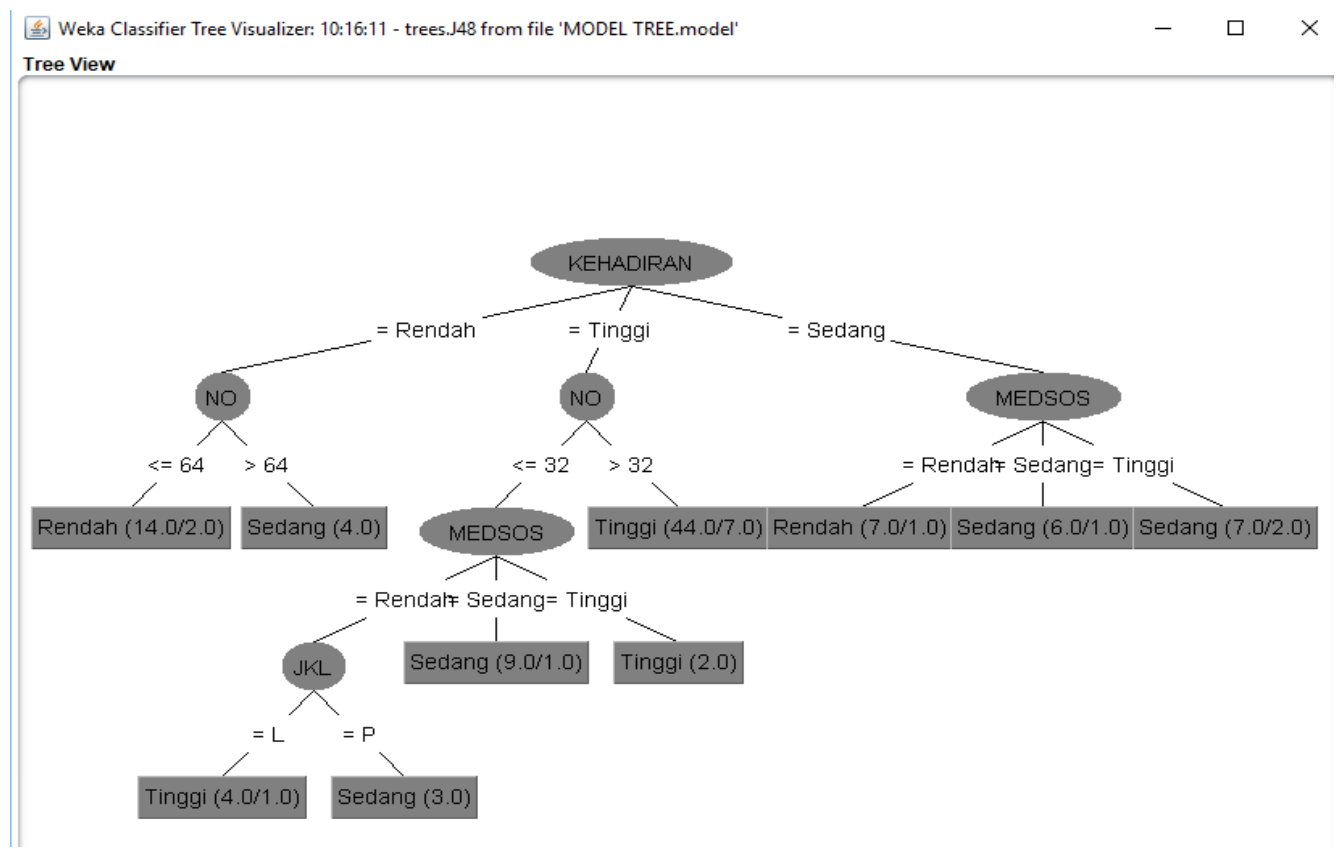

\section{Gambar 6. Hasil Analisis WEKA}

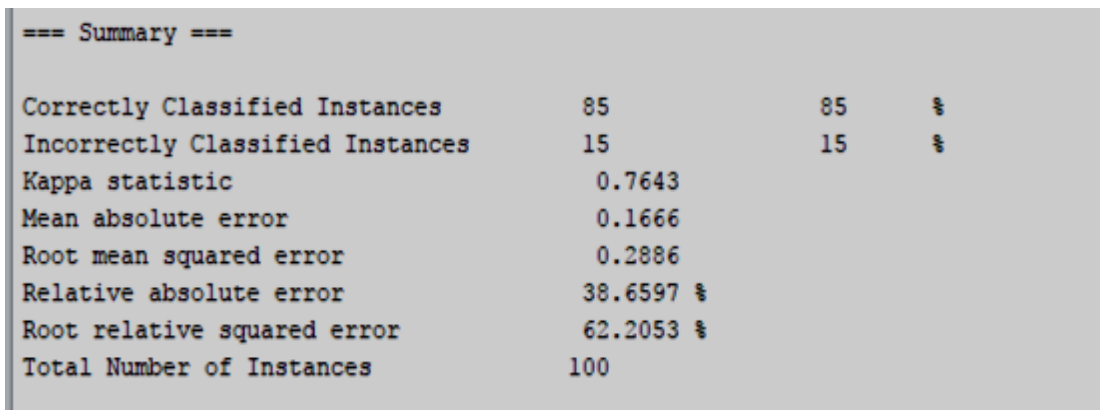

Gambar 7. Hasil Summary

Data statistik yang didapatkan menyatakan bahwa bahwa $84 \%$ mahasiswa memiliki IPK kategori Tinggi dan sisanya $16 \%$ mahsiswa memiliki IPK kategori sedang. Sedangkan untuk kategori IPK bernilai Rendah tidak memilik prosentase. Sebanyak $49 \%$ responden yang dianalisis merupakan berjenis kelamin perempuan dan $51 \%$ sisanya adalah berjenis kelamin Laki-laki. Analisis data selanjutnya yaitu mencari nilai signifikan keterkaitan antara beberapa variable seperti media social terhadap IPK dan Waktu Belajar terhadap IPK. Ada 2 jenis hipotesis yang telah diuji menggunakan metode Chi kuadrat yaitu H1 yang pertama adalah "Penggunaan Media Sosial memberikan pengaruh negative bagi nilai akademik (IPK) mahasiwa UMTAS". Sedangkan Hipotesis yang kedua adalah H1 berupa "Waktu Belajar mahasiwa memberi dampak positif terhadap nilai IPK".

Pada tabel 1 yang memperlihatkan hasil analisis chi-square test dapat diketahui bahwa nilai signifikansi p-value sebesar 0.003 . Karena nilai signifikansi $0.003<(0.05)$ maka hipotesis H1 diterima yang berarti bahwa ada hubungan antara penggunaan media social terhadap perolehan nilai IPK mahasiswa. Sedangkan pada tabel 1 diektahui bahwa nilai signifikansi p-value sebesar 0.465 . Karena nilai signifikansi 0.465> (0.05) maka hipotesis null diterima yang berarti bahwa tidak ada hubungan antara Waktu yang digunakan mahasiswa untuk belajar terhadap perolehan nilai IPK mahasiswa. 
Tabel 1. Hasil uji untuk medsos terhadap IPK

\begin{tabular}{llll}
\hline Item & Value & df & Asymp. Sig. (2-sided) \\
\hline Pearson Chi-Square & 15.866 & 4 & .003 \\
Likelihood Ratio & 19.917 & 4 & .001 \\
Nof Valid Cases & 150 & & \\
\hline
\end{tabular}

Ada 150 data terlihat jelas pada $N$ of Valid Cses di dua tabel yang mengartikan bahwa seluruh data yang diinputkan telah diproses dengan baik dan tidak ada data yang hilang (Missing Value). Hasil analisis dari proses penghitungan chi-square ini dicermati melalui hasil pada tabel yang merupakan Asymp sig. Hasil dari kolom tersebut merupakan hasil signifikansi yang dapat menerima atau menolak suatu kasus.

Tabel 2. Waktu belajar terhadap IPK

\begin{tabular}{llll}
\hline Item & Value & df & Asymp. Sig. (2-sided) \\
\hline Pearson Chi-Square & 3.586 & 4 & .465 \\
Likelihood Ratio & 3.502 & 4 & .478 \\
N of Valid Cases & 150 & & \\
\hline
\end{tabular}

Hasil studi kasus yang telah dilakukan memberikan gambaran bahwa perkembangan produk teknologi informasiherupa media sosial mulai memberikan pengaruh terhadap generasi muda dalam kegiatan belajar. Hal tersebut memberikan dampak cukup mengganggu karena konsentrasi yang seharusnya difokuskan untuk belajar di kelas maupun diluar kelas menjadi terpecah karena ketertarikan mereka terhadap medsos.

Penyesuaian dalam mengikuti era teknlogi skarang butuh perhatian yang khusus dari para pendidik maupun orang tua dikarenakan hasil angka berdasarkan analisis data menunjukan angka yang perlu diwaspadai karena terjadi signifikansi yang cukup nyata. Kasus yang sama akan banyak terjadi di lingkungan pendidikan lainnya dikarenakan fakta pengaruh teknologi yang ada sudah banyak menghasilkan dampak dampak yang perlu diwaspadai oleh orang sekitar.

\section{KESIMPULAN}

Penerapan Data mining dapat digunakan salah satunya untuk memprediksi kategori perolehan IPK ahasiswa. Pada penelitian ini, prediksi nilai IPK mahsiswa memperlihatkan bahwa terdapat $84 \%$ mahasiswa memiliki IPK tinggi dan sisanya 16\% memiliki nilai IPK Sedang. Dari pengukuran kinerja algoritma yang telah dilakukan, dapat disimpulkan untuk kasus ini algoritma C4.5 atau J48 dari algoritma pada mesin WEKA memiliki nilai akurasi sebesar $85 \%$. Dalam hal ini berarti penggunaan algoritma masih ditemukan $15 \%$ tingkat kesalahan atau error.

Berdasarkan analisi data dengan metode Chi Kuadrat didapatkan bahwa adanya hubungan antara waktu beraktifitas pada media social terahadap nilai IPK mahsiswa dengan nilai probabilitas sebesar 0.003. Sedangkan terdapat nilai probabilitas sebesar 0.465 yang menyatakan tidak adanya hubungan yang signifikan antara Waktu belajar mahsiswa Terhadap perolehan nilai IPK mahasiswa.

Untuk penelitian yang selanjutnya disarankan agar pengujian algortima c4.5 bisa digunakan untuk lebih banyak atribut lagi dan pengujian keterkaitan hubungan antara beberapa variable dengan beberapa hipotesis tambahan yang lebih banyak agar terlihat variasi perbedaannya.

\section{UCAPAN TERIMA KASIH}

Terimakasih kepada Lembaga Penelitian dan Pengabdian Masyarakat (LPPM) di Universitas Muhammadiyah Tasikmalaya yang telah memberikan dukungan materi sehingga penelitian ini dapat berjalan lancar dan selesai hingga dapat masuk ke proses publikasi. Begitu juga pada tim peneliti dalam naskah ini yang turut serta membantu hingga menyelesaikan naskah publikasi ini.

\section{DAFTAR PUSTAKA}

[1] Adebiyi, A., Akinbode, M., Okuboyejo, S., Et Al. (2015). Social Networking And Students' Academic Performance: The Role Of Attention Deficit, Predictors Of Behavior And Academic Competence. Retrieved From Http://Eprints.Covenantuniversity.Edu.Ng/5336/

[2] Apjii. (2016). Asosiasi Penyelenggara Jasa Internet Indonesia. Retrieved January 24, 2017, From Https://Www.Apjii.Or.Id/ 
[3] Boyd, D. M., \& Ellison, N. B. (2007). Social Network Sites: Definition, History, And Scholarship. Journal Of Computer-Mediated Communication, 13(1), 210-230. Https://Doi.Org/10.1111/J.10836101.2007.00393.X

[4] Briyan Anugerah Pekerti, D. Oleh M. (2013, December 29). Pengaruh Jejaring Sosial Terhadap Kelakuan Seseorang [Jurnal Ilmiah]. Retrieved January 24, 2017, From Http://Jurnalilmiahtp2013.Blogspot.Com/2013/12/Pengaruh-Jejaring-Sosial-Terhadap_4257.Html

[5] Erna Oneto, \& Yosep S. (2009). Antigaptek Internet. Jakarta: Andi.

[6] Fayyad, U. M. (Ed.). (1996). Advances In Knowledge Discovery And Data Mining. Menlo Park, Calif.: Aaai Press [U.A.].

[7] Fitri, S. (2014). Perbandingan Kinerja Algoritma Klasifikasi Naïve Bayesian, Lazy-Ibk, Zero-R, Dan Decision Tree- J48. Dasi, 15(1), 33.

[8] Hasnain, H., Nasreen, A., \& Ijaz, H. (2015). Impact Of Social Media Usage On Academic Performance Of University Students. International Research Management \& Innovation Conference. Retrieved From Http://Rmc.Kuis.Edu.My/Irmic/Wp-Content/Uploads/2014/12/Impact-Of-SocialMedia-Usage-On-Academic-Performance-Of-University-Students.Pdf

[9] Kalra, R. K., \& Manani, P. (2013). Effect Of Social Networking Sites On Academic Achievement Among Introverts And Extroverts. Asian Journal Of Social Sciences \& Humanities, 2(3), 401-406.

[10] Kodir, A. (2010). Pengenalan Internet (Revisi). Yogyakarta: Andy.

[11] Mukhlason, A., \& Aljawiy, A. Y. (2012). Jejaring Sosial Dan Dampak Bagi Penggunanya. Teknologi, 1(1). Retrieved From Http://Journal.Unipdu.Ac.Id/Index.Php/Teknologi/Article/View/46

[12] Nasution, N., Djahara, K., \& Zamsuri, A. (2015). Evaluasi Kinerja Akademik Mahasiswa Menggunakan Algoritma Naïve Bayes (Studi Kasus: Fasilkom Unilak). Digital Zone: Jurnal Teknologi Informasi Dan Komunikasi, 6(2). Retrieved From Https://Ejurnal.Unilak.Ac.Id/Index.Php/Dz/Article/View/151

[13] Sharma, A. K., \& Sahni, S. (2011). A Comparative Study Of Classification Algorithms For Spam Email Data Analysis. International Journal On Computer Science And Engineering, 3(5), 1890-1895.

[14] Singgih, S. (2014). Panduan Lengkap Spss Versi 20. Jakarta: Gramedia. 